\title{
BRONCOESPASMO DURANTE ANESTESIA PARA COELHO SUBMETIDO A APENDICETOMIA: RELATO DE CASO
}

\section{ARTIGO ORIGINAL}

BEDIN, Rafael Antonio Caldart ${ }^{1}$

SCHULTZ, Maisa ${ }^{2}$

BEDIN, Antonio ${ }^{3}$

BEDIN, Rafael Antonio Caldart. SCHULTZ, Maisa. BEDIN, Antonio. Broncoespasmo durante anestesia para coelho submetido a apendicetomia: Relato de caso. Revista Científica Multidisciplinar Núcleo do Conhecimento. Ano 05, Ed. 06, Vol. 03, pp. 159-166. Junho de 2020. ISSN: 2448-0959, Link de acesso: https://www.nucleodoconhecimento.com.br/saude/broncoespasmo

\section{RESUMO}

A anestesia para animais de laboratório é motivo de preocupação biomédica e um dos dilemas mais conflitantes no debate bioético. O uso de anestésicos em cirurgia experimental é feito para promover a contenção do animal, de forma a atingir um grau razoável de relaxamento muscular e de produzir analgesia suficiente. Esta prática requer utilização de protocolos para a administração de doses seguras e eficientes. Este relato é sobre coelho da raça Nova Zelândia submetido a anestesia geral. Para a medicação pré-anestésica foi utilizado acepromazina $1 \mathrm{mg} \cdot \mathrm{kg}^{-1}$ associada a cetamina $15 \mathrm{mg} \cdot \mathrm{kg}^{-1}$ via subcutânea. Para a manutenção da anestesia foi utilizado isoflurano e oxigênio com a utilização de máscara laríngea número 1 e sistema inalatório Mapleson D sob respiração espontânea. Logo após a locação da máscara

\footnotetext{
${ }^{1}$ Graduando em medicina.

2 Graduanda de medicina.

${ }^{3}$ Médico Anestesiologista. Mestre em Saúde. Doutor em Anestesiologia.
} 
laríngea observou-se dificuldade respiratória. $\mathrm{Na}$ ausculta observou-se sibilos em ambas as bases pulmonares. Foi administrado dexametasona $500 \mathrm{mcg}$ venosa e adrenalina $50 \mathrm{mcg}$ subcutânea. Por 10 minutos foi mantido a ventilação controlada manual e posteriormente retornou-se à ventilação espontânea. Os ruídos adventícios reduziram e o procedimento transcorreu sem outras intercorrências.

Palavras Chaves: Coelhos, isoflurano, anestesia geral.

\section{INTRODUÇÃO}

A anestesia para animais de laboratório é motivo de preocupação biomédica e um dos dilemas mais conflitantes no debate bioético (BEDIN et al., 2013). O uso de anestésicos em cirurgia experimental é feito para promover a contenção do animal, de forma a atingir um grau razoável de relaxamento muscular e de produzir analgesia suficiente. Esta prática requer utilização de protocolos para a administração de doses seguras e eficientes (BEDIN et al., 2013; LELE et al., 2013).

\section{REVISÃO BIBLIOGRÁFICA}

Os procedimentos anestésicos em leporinos devem seguir um escalonamento de intensidade, pois é possível se obter desde sedação medicamentosa leve até planos profundos de anestesia, os quais permitem intervenções cirúrgicas maiores (RAILLARD et al., 2019). Anestesias gerais com agentes halogenados é escolha frequente para procedimentos cirúrgicos de curta ou longa duração onde se busca a manutenção da homeostasia do meio interno o mais próximo dos valores préoperatórios. A técnica consiste em se administrar medicação pré-anestésica, aguardar 15 minutos e adaptar a máscara facial conectada ao aparelho de anestesia equipado com vaporizador de agentes inalatórios. Pode-se utilizar $\mathrm{O}_{2}$ de 50 a $100 \%$ e isoflurano de 1 a 2,5 \% (BEDIN et al., 2013; RAILLARD et al., 2019; TUNCALI et al., 2018).

A manutenção de via aérea é tecnicamente complexa em coelhos. A visualização da glote com laringoscópio é muito difícil (BEDIN et al., 2013). Por este motivo 
frequentemente se utiliza a intubação às cegas com a orientação pela respiração. Muitos pesquisadores utilizam traqueostomia de rotina ou máscara laríngea (THOMPSON et al., 2017). A anestesia em coelhos pode, com frequência, ser mantida sob máscara de oxigênio e halogenado em respiração espontânea (BEDIN et al., 2013; RAILLARD et al.,, 2019). Quando existe a necessidade de ventilação esta pode realizada de forma manual em sistema simples (Mapleson D) ou controlada mecânica em aparelho com filtro circular e fole.

A monitorização do procedimento anestésico tem como base clínica através de frequência cardíaca, frequência respiratória, coloração de mucosas e reflexos oculares e palpebrais. A rotina conta com ausculta com estetoscópio precordial e oximetria de pulso. Outros monitores podem ser utilizados de acordo com as condições e parâmetros integrantes do protocolo do estudo, desta forma pode ser útil capnografia, pressão arterial invasiva, gasometria arterial, entre outros. O período pós-operatório faz parte do protocolo anestésico, sendo fundamental os cuidados ministrados ao animal neste momento. Complicações podem ocorrer, tais como depressão respiratória e distúrbios do ritmo cardíaco. Após o término do procedimento anestésico-cirúrgico os coelhos são transportados para a recuperação anestésica em gaiolas isoladas (BEDIN et al., 2013).

O local de recuperação deve ser calmo e com poucos ruídos, sem muita luz, também, deve-se evitar o estresse procurando o mínimo de manipulação do animal. Se no protocolo do estudo estiver previsto eutanásia as técnicas para sua realização devem buscar bom padrão de sedação prévia. O ideal significa que a técnica deve minimizar a ansiedade experimentada pelo animal antes da perda da consciência. Para eutanásia as técnicas mais frequentes são $\mathrm{CO}_{2}$ inalado, anestésicos inalatórios halogenados em dosagens elevadas, barbitúricos venosos e cloreto de potássio venoso, sendo este último somente utilizado sob sedação profunda prévia pois a injeção venosa de cloreto de potássio costuma ser dolosa. Com base nestes dados da literatura tem sido adotado como procedimento anestésico utilizado como rotina pela disciplina de Técnica Operatória e Anestesiologia do Curso de Medicina da 
Universidade da Região de Joinville (UNIVILLE) para anestesia em coelhos (BEDIN et al., 2013):

1. Realizada a identificação e pesagem pois são partes integrantes do préoperatório. Após a pesagem do animal, o mesmo deve ser identificado com um esparadrapo na pata dianteira com seu número e o peso correspondente.

2. Para a medicação pré-anestésica: acepromazina $1 \mathrm{mg} \cdot \mathrm{kg}^{-1}$ associada com dexametasona $0,2 \mathrm{mg} \cdot \mathrm{kg}^{-1}$ mais cetamina $15 \mathrm{mg} \cdot \mathrm{kg}^{-1}$ subcutâneo quinze minutos antes do início da tricotomia.

3. A tricotomia deve ser realizada $\mathrm{n}$ região anterior do pescoço, abdômen e margem da orelha.

4. Imobilização sobre a mesa operatória.

5. Para o acesso venoso: utilizado a veia marginal da orelha, sendo cateter $24 \mathrm{G}$. Instalação de soro fisiológico 0,9\% $250 \mathrm{ml}$.

6. Anestesia: cetamina 5 a $10 \mathrm{mg} . \mathrm{kg}-1$ venosa. Via aérea mantida com máscara laríngea número 1. Em certas situações (cirurgias torácicas) se procede a intubação traqueal com cânula número 2 ou 3 ou traqueostomia.

7. Para a monitorização utiliza-se estetoscópio precordial (ou esofágico), eletrocardioscopia (se disponível) e oximetria de pulso (se disponível).

8. Anestesia inalatória para manutenção: isoflurano a $1 \%$ a $3 \%$ com oxigênio dois a três litros por minuto sob máscara laríngea em sistema Mapleson D.

9. Elaboração da ficha de anestesia: sinais vitais a cada 5 a 10 minutos.

10. Período imediato pós-anestésico sendo do início da recuperação até o restabelecimento da consciência e padrões fisiológicos.

11. Para dor pós-operatória utiliza-se paracetamol ou dipirona por via oral entre 10 a $15 \mathrm{mg} \cdot \mathrm{kg}^{-}{ }^{-1}$, três vezes ao dia.

12. Quando no protocolo está previsto a eutanásia esta poderá ser feita com $\mathrm{CO} 2$ a $10 \mathrm{I} \cdot \mathrm{min}^{-1}$ por até 10 minutos. A segunda escolha poderá ser cloreto de potássio a 19,1\% $1 \mathrm{ml}^{\mathrm{kg}}{ }^{-1}$ venoso, porém com o coelho anestesiado com cetamina 1 a 10 mg. $\mathrm{kg}^{-1}$ venosa ou cetamina 10 a $50 \mathrm{mg} \cdot \mathrm{kg}^{-1}$ subcutânea quinze minutos antes (BEDIN et al., 2013; CARDOSO et al., 2020; SAYCE et al., 2020; UZUN et al., 2015). 


\section{RELATO DO CASO}

A anestesia que faz parte deste relato foi autorizada pelo Comitê de Ética em Pesquisa no Uso de Animais da Universidade da Região de Joinville (CEUA) número 0103/2018. Este é o relato de coelho da raça da nova Zelândia que foi submetido à laparotomia para apendicectomia demonstrativa. Durante a avaliação pré-anestésica observou-se que se tratava de coelho de 3240 gramas e sem anormalidades na ausculta cardíaca ou pulmonar (murmúrios vesiculares estavam audíveis bilateralmente e não foi auscultado ruídos adventícios).

Para a medicação pré-anestésica foi utilizado acepromazina $1 \mathrm{mg} \cdot \mathrm{kg}^{-1}$ associada a cetamina 15 mg. $\mathrm{kg}^{-1}$ subcutânea. Para a manutenção da anestesia foi utilizado isoflurano e oxigênio em vaporizador universal com a utilização de máscara laríngea número 1 e sistema inalatório Mapleson D sob respiração espontânea.

A hidratação foi com soro fisiológico $10 \mathrm{ml}^{\mathrm{kg}} \mathrm{kg}^{-1}$ (tabela 2). Utilizou-se colchão térmico. Para a monitorização foi utilizado estetoscópio precordial, eletrocardioscopia, oximetria de pulso e parâmetros clínicos (movimentos involuntários, reflexo oculopalpebral). Logo após a locação da máscara laríngea observou-se dificuldade respiratória.

$\mathrm{Na}$ ausculta observou-se sibilos em ambas as bases pulmonares. Foi administrado dexametasona $500 \mathrm{mcg}$ venosa e adrenalina $50 \mathrm{mcg}$ subcutânea. Por 10 minutos foi mantido a ventilação controlada manual e posteriormente se retornou à ventilação espontânea. Os ruídos adventícios reduziram e o procedimento transcorreu sem outras intercorrências. A anestesia durou 67 minutos e o procedimento cirúrgico 56 minutos. Para a eutanásia utilizou-se cetamina $10 \mathrm{mg} \cdot \mathrm{kg}^{-1}$ venosa seguida 5 a 15

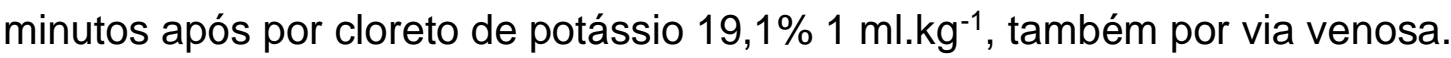

\section{DISCUSSÃO}

Os anestésicos inalatórios voláteis exercem um efeito protetor diferenciado contra o desenvolvimento do broncoespasmo após estimulação colinérgica (MYERS et al., 
2011a). No entanto, sua capacidade de inibir as consequências respiratórias adversas de uma reação anafilática após a exposição a um alérgeno não foi caracterizada (LELE e et al., 2013). Em coelhos anestesiados as alterações nas resistências pulmonares induzidas pelo ar frio inspirado foram estudadas.

As respostas das vias aéreas ao frio foram avaliadas em animais hígidos e em coelhos sensibilizados pela albumina sérica de bovinos (LELE et al., 2013). A magnitude do broncoespasmo induzido pelo frio foi significativamente maior nos coelhos sensibilizados do que nos normais (LELE et al., 2013). Os animais mostraram uma hiperresponsividade tanto à histamina quanto ao ar frio.

Esses resultados sugerem que o broncoespasmo induzido pelo frio resulta de um reflexo vagal mediado cujos efeitos são apenas aumentados e prolongados por uma liberação local de fatores humorais, ligados ao caminho reflexo. O aumento da resposta ao ar frio nos coelhos parece corresponder à hiperresponsividade inespecífica do músculo liso brônquico, e não a um aumento da liberação local de mediadores inflamatórios (MYERS et al., 2011a).

A combinação do efeito de estresse e anestésicos pode resultar em intercorrências respiratórias e cardíacas. Além do estresse pode haver presença de infecção respiratória por Pasteurella multocida que pode ser mais um fator para intercorrências respiratórias durante o ato anestésico (HERRERA et al., 2017).

Por este motivo no exame pré-operatório de coelhos devemos prestar especial atenção à presença de coriza o que pode ser um indicativo de infecção respiratória. Se o estímulo contrátil for de origem colinérgica, o sevoflurano e o desflurano exercem potenciais broncoprotetores semelhantes para atuar contra a constrição pulmonar, independentemente da presença de broncoespasmo (MYERS et al., 2011b). Desta maneira, podem os anestésicos voláteis serem úteis para melhorar a ventilação em situações quando se tem a presença de broncoespasmo (LELE et al., 2013). A adrenalina, isoflurano e dexametasona podem ser úteis no manejo do broncoespasmo em coelhos (LELE et al., 2013; MYERS et al., 2011a). 


\section{CONCLUSÃO}

Nas anestesias de longa duração, como as laparotomias, recomenda-se e a utilização de medicação pré-anestésica e posteriormente a indução anestésica feita pela combinação de agentes. Entretanto, o manejo anestésico requer monitoração para evitar que doses insuficientes ou exageradas ocorram. Para evitar que variações fisiológicas importantes ocorram, recomenda-se a monitorização contínua dos sinais vitais desde o início do procedimento anestésico-cirúrgico todo o período durante o qual a anestesia é mantida, até a eutanásia ser realizada (STEINER et al., 2019).

\section{REFERÊNCIAS}

BEDIN, Antonio e JUNIOR, Harry e KRELING, Patricia. Anestesia para cirurgia experimental em coelhos. v. 42, n. 2, p. 33-37, 2013.

CARDOSO, Clarisse G. e colab. A comparative study of the cardiopulmonary and sedative effects of a single intramuscular dose of ketamine anesthetic combinations in rabbits. Research in veterinary science, v. 128, p. 177-182, $1 \mathrm{Fev}$ 2020. Disponível em: <http://www.ncbi.nlm.nih.gov/pubmed/31812610>. Acesso em: 10 fev 2020.

HERRERA, María e colab. Effect of premedication with subcutaneous adrenaline on the pharmacokinetics and immunogenicity of equine whole $\lg G$ antivenom in a rabbit model. Biomedicine and Pharmacotherapy, v. 90, p. 740-743, 1 Jun 2017. Disponível em: <http://www.ncbi.nlm.nih.gov/pubmed/28419970>. Acesso em: 7 fev 2020.

LELE, Eniko e colab. The protective effects of volatile anesthestics against the bronchoconstriction induced by an allergic reaction in sensitized rabbit pups. Anesthesia and Analgesia, v. 116, n. 6, p. 1257-1264, Jun 2013.

MYERS, Carole F. e colab. Sevoflurane and desflurane protect cholinergicinduced bronchoconstriction of hyperreactive airways in rabbits. Canadian Journal of Anesthesia, v. 58, n. 11, p. 1007-1015, Nov 2011 a. 
MYERS, Carole F. e colab. Sevoflurane and desflurane protect cholinergicinduced bronchoconstriction of hyperreactive airways in rabbits. Canadian Journal of Anesthesia, v. 58, n. 11, p. 1007-1015, Nov 2011b. Disponível em: <http://www.ncbi.nlm.nih.gov/pubmed/21887602>. Acesso em: 7 fev 2020.

RAILLARD, Mathieu e colab. Anaesthetic and perioperative management of 14 male new zealand white rabbits for calvarial bone surgery. Animals, v. 9, n. 11, 1 Nov 2019.

SAYCE, Lea J e colab. Continuous Rate Infusion of Ketamine Hydrochloride and Dexmedetomidine for Maintenance of Anesthesia during Laryngotracheal Surgery in New Zealand White Rabbits (Oryctolagus cuniculus). Journal of the American Association for Laboratory Animal Science, 31 Jan 2020. Disponível em: $<$ https://www.ingentaconnect.com/content/10.30802/AALAS-JAALAS-19-000076>. Acesso em: 10 fev 2020.

STEINER, Aline R. e colab. Humanely ending the life of animals: Research priorities to identify alternatives to carbon dioxide. Animals, v. 9, n. 11, $1 \mathrm{Nov}$ 2019.

THOMPSON, Krista L. e MEIER, Thomas R. e SCHOLZ, Jodi A. Endotracheal intubation of rabbits using a polypropylene guide catheter. Journal of Visualized Experiments, v. 2017, n. 129, 13 Nov 2017.

TUNCALI, Bahattin e colab. Retrospective Evaluation of Patients who Underwent Laparoscopic Bariatric Surgery. Turkish Journal of Anesthesia and Reanimation, v. 46, n. 4, p. 297-304, 16 Ago 2018. Disponível em: <http://www.ncbi.nlm.nih.gov/pubmed/30140537>. Acesso em: 29 set 2019.

UZUN, Metehan e colab. The investigation of airway management capacity of vgel and cobra-PLA in anaesthetised rabbits. Acta Cirurgica Brasileira, v. 30, n. 1, p. 80-86, 2015.

Enviado: Abril, 2020. 
Aprovado: Junho, 2020. 